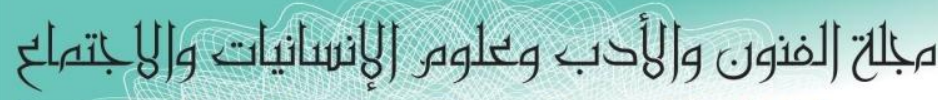

Journal of Arts, Literature, Humanities and Social Sciences

ISSN online: 2414 - 3383

ISSN print: 2616 - 3810
أيلول - سبتمبر 2019

العدد (43)

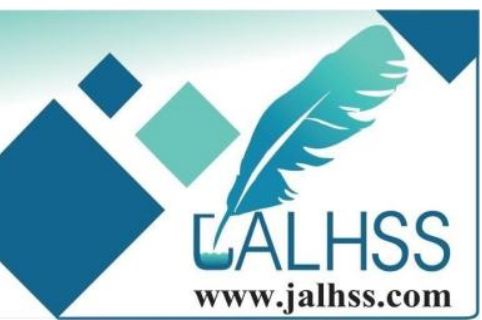

\title{
Kinetic Facades the new Paradigm Shift in Architecture toward an Environmental Design Performance
}

\author{
Azza Osman Bakr \\ Lecturer \\ Faculty of applied arts \\ Damietta University - Egypt \\ e.mail: azzaosmanbakr@gmail.com
}

\begin{abstract}
There has been an interest in interactive, responsive, and intelligent architecture, particularly in the 1960s and 1970s. The new paradigm shift in architecture coincides with advancements in computer science, cybernetics, and building technology that have altered the architecture from a static form to a more kinetic and dynamic form.

Kinetic Architecture considers one of the time consequences that is associated with concepts of utility, technology, and beauty. These concepts have a great effect on the progress of society and human through his vision to the advanced needs along with the time that affects the role of technology to serve the human through shedding light on the relationship between these effects and the human to reach a new architecture outcome, that is Kinetic Architecture. This outcome interacts with the human existence of society through several factors that can be used in a communicative way with society in general and therefore the human sees its impact as an outcome of an aesthetic, functional, and technical action. This is what the research spotted the light on by clarifying the connection of the kinetic formality elements of the building through the design process and the impact of this movement on the recipient.

The origin of the word kinetic is Greek, pertaining to, or caused by motion, thus the main aspect is the motion and integration within the context of the surrounding environment or occupant.

Among strategies and solutions used in discussing the problem of a buildings' energy consumption, the buildings' facade should function as a mediator between the external and internal environments. Facades can be entrusted with multiple vital functions that dictate the building's energy consumption and which determine indoor environmental quality.
\end{abstract}




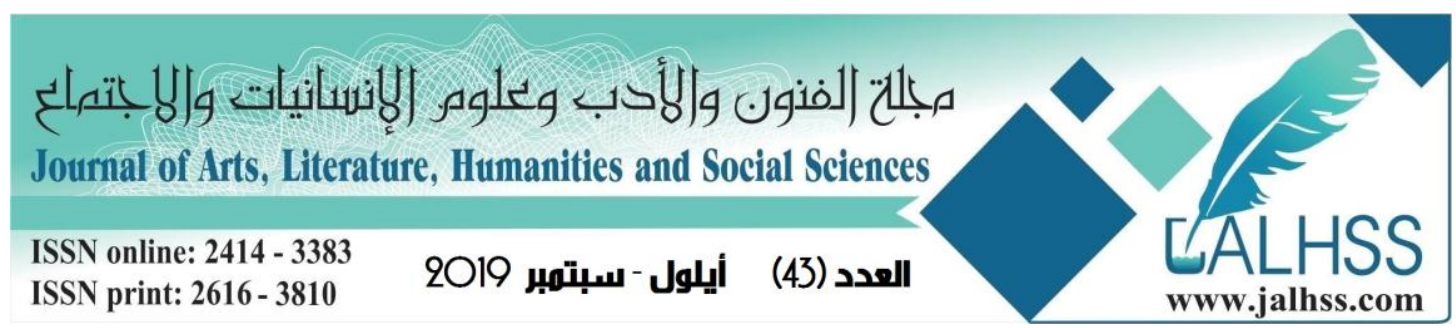

\section{The Problem:}

Traditionally the design of a buildings' facade is 'static', where the external environmental boundary conditions are designed to be constantly changing. As a result, traditional facades are not capable of adapting and responding to various changes that they are exposed to.

\section{The Aim:}

From this perspective, building innovation and technology should be a catalyst that provides the necessary momentum for a significant leap in ideas with implementations moving forward. Consequently, the concept of responsive facades has been described using multiple terms in the literature, however the definition of responsive facades shows that the term presents a specific form of response that is a kinetic response.

It also aims at introducing a cognitive framework that contributes to the clarification of kinetic architecture through the construction of a theoretical framework that links between the movement in architecture and its relation to the recipient.

The research follows the inductive method of collecting information and data, followed by the analytical descriptive approach to analyze a group of dynamic facades in an attempt to identify some of the forms of dynamic technology used in the design of dynamic facades.

The study shows that the applications and cases listed in this document, building façades have a great role in establishing energy effectiveness and energy execution where: Kinetic façades are used frequently to allow natural light. It is viewed as an effective inventive lighting and ventilation framework if appropriately structured.

\section{Introduction}

The desire for transparency in buildings in contemporary architecture where opaque building elements are increasingly replaced by transparent elements makes the use of glass as a construction material more and more desirable. On top of that, the realization of glass constructions is becoming increasingly challenging together with the growth of expectations. Numerous recent projects around the world clearly demonstrate this trend. The rapid development of research and production techniques adds to the increased use of this material, which can be considered special amongst other known materials due to its high light transmission ability, allowing views to the exterior and daylight entrance into enclosed spaces. The decisive impact of research and production techniques is undoubtedly one of the key factors in this trend.

There has been an interest in interactive, responsive, and intelligent architecture, particularly in the 1960s and 1970s. The new paradigm shift in architecture coincides with advancements in computer science, cybernetics, and building technology that have 


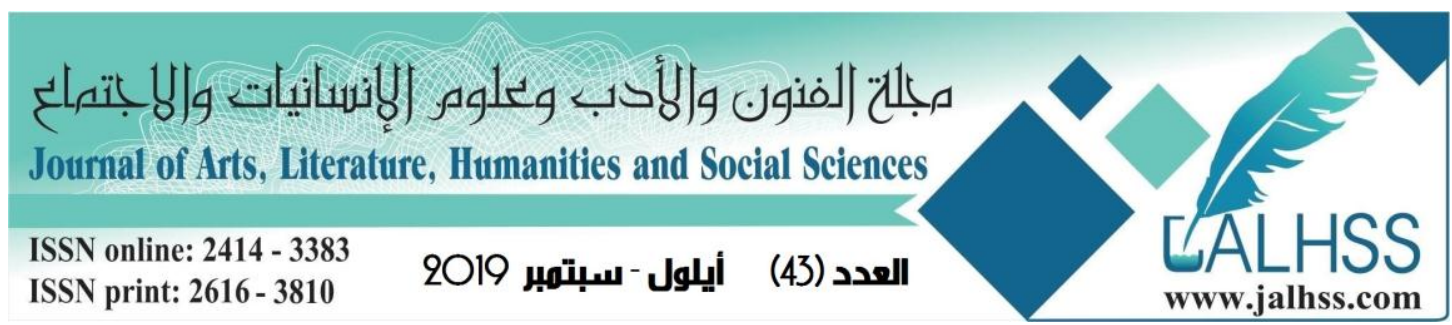

altered the architecture from a static form to a more kinetic and dynamic form. The origin of the word kinetic is Greek, pertaining to, or caused by motion. Thus, the main aspect is the motion and integration within the context of the surrounding environment or occupant.

Historically, buildings have provided shelter and protection to people from external conditions such as extreme heat or cold. The building envelope acts as a physical barrier between interior and exterior environments. It functions as an outer shell to help maintain indoor comfort while facilitating climate control. Today's improvement of building services application such as in lighting, heating, ventilation, and air-conditioning, has been assigned to enhance the performance of indoor environment and thermal comfort. Consequently, external building envelopes are starting to lose their role as a moderator of energy and comfort and therefore, a building place and significant energy burden on maintaining optimal condition in building indoor environment.

Among strategies and solutions used in discussing the problem of a buildings' energy consumption, the buildings' façade should function as a mediator between the external and internal environments. Façades can be entrusted with multiple vital functions that dictate the building's energy consumption that determines indoor environmental quality.

\section{Kinetic Façades:}

Kinetic Façades describe the actual movement or motions through geometric transformation in space that affects the changing state, material properties, or physical structure of the building façades without compromising the overall structural integrity. Applications of kinetic façades are to enhance the aesthetic qualities, respond to the change of environmental conditions, and perform functions that would be impossible for the static façades.

A kinetic façade is one that changes dynamically rather than being static or fixed, allowing movement to occur on a building's surface. This helps to create what the architect Buckminster Fuller called a 'skin-like articulation' effect, and is an extension of the idea that a building's envelope is an active system rather than just a container. In addition, it can be used to manage light, air, energy, and even information. They can act to reduce solar gain as well as allowing the passage of fresh air into the building, helping to alter the interior environment. The moving elements of the façade can be programmed to respond to climatic or other environmental factors, time, levels and type of occupancy, and so on to improve performance and efficiency. With advances in sensors, materials, and building management technology, designers are increasingly able to consider kinetic components as design solutions.

Buildings that fall into this category include Al Bahr Towers in Abu Dhabi in the United Arab Emirates which has computer-controlled façade made of umbrella-like panels which open and close in response to the sun's movement through the day, to 


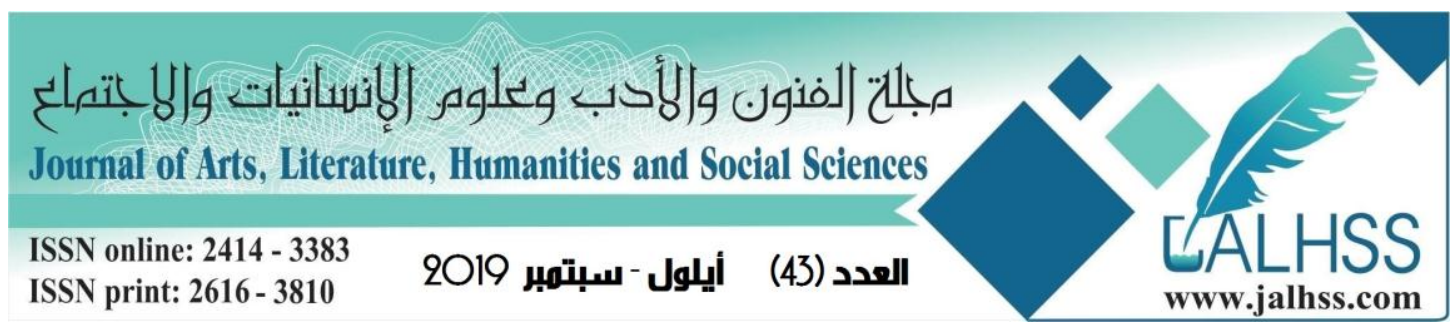

achieve optimal shading and light entering the building.

For instance, a building's energy requirements can be considerably lowered if its design can adapt to diurnal fluctuations in temperature. An adaptive system that is modulated to control the volume and direction of heat flow in response to external and internal conditions can enhance comfort and energy performance. Many studies suggest that the role of the kinetic façade to improve the energy performance of buildings could be significant. The kinetic façade systems can decrease environmental impacts and help to reduce reliance on mechanical systems for the building's energy. Moreover, the façade helps to generate power, particularly electricity, with building-integrated photovoltaic systems (BIPV). In the study, they conduct a simulation performance for a prototype façade kinetic system. The results indicate that these kinetic façade systems can reduce energy consumption by approximately $30 \%$ more than the non-shade system for both heating and cooling. Another study demonstrates the potential of kinetic façade systems to provide appropriate daylight levels by using light-deflection techniques in intelligent kinetic façades to improve indoor lighting. The study also shows that kinetic façades have an outstanding ability to enhance the lumen performance of the indoor environment over conventional façades. One study, however, reviewed the current practice of kinetic envelopes and claimed that current strategies led to large energy savings in buildings for indoor comfort, visual qualities, and occupant interaction. Occupant interaction is an important factor, because the kinetic façade promises to boost occupant satisfaction, leading to increased work productivity. On the other hand, the kinetic façade systems have high initial costs and need constant maintenance.

\section{Concept of kinetic façades:}

The façade is a strategic element because it is the most visible part of the building. This leads to an improvement in environmental and appearance performances of a building. The façade also exchanges energy with the external environment, this increases energy performance. The façade protects structures and interiors of the building and this contributes to the extension of the life of the building. Thus, the building's façade should function as a mediator between the external and internal environments that can be entrusted with multiple vital functions that dictate the building's energy consumption and determine the indoor environmental quality. Dynamic façades are "façades with the ability to respond to their environment by either typological change of material properties that alter the overall form or local alteration by regulating their energy consumption to reflect the environmental conditions that surround it".

The environment is the key factor that affects the design of façades, the amount of layering, and the material choice; all is dependent on these external forces. Therefore, 


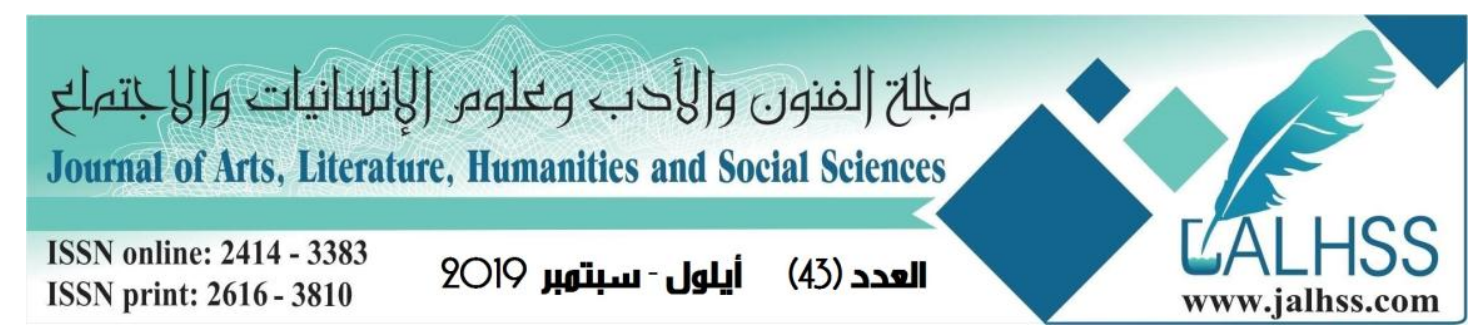

there are several types of dynamic façades:-

\section{A. User Control Kinetic Façade}

The user control system is an automated system that provides solutions for some time to convey the actuated and responsive reactions to passive processes. Fig (1)
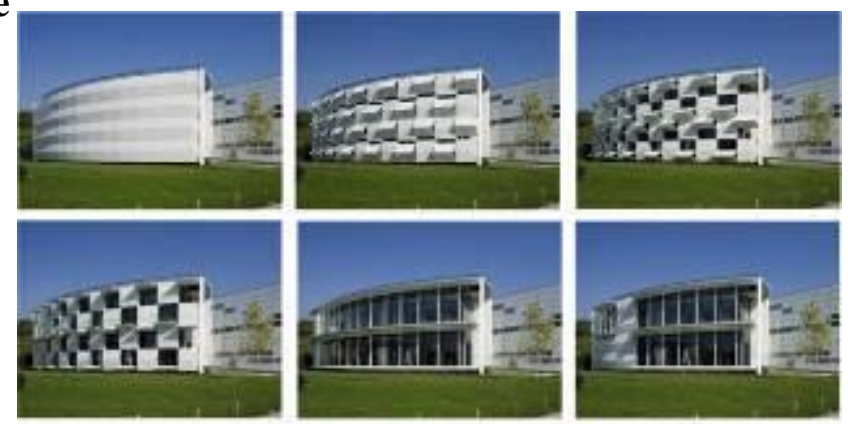

Fig (1)

The Kiefer Technic Showroom by Ernst Gieselbrecht + Partner, a built project located in Steiermark, Austria (2007)
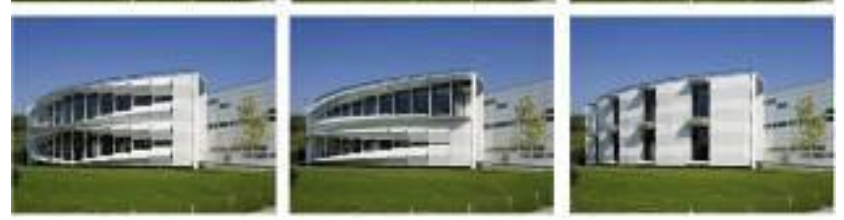

B. Light Projection and Light Control Kinetic Façade The building Galleria Centercity in Cheonan, Korea fits the criteria of light projection kinetic façade Fig (2). The building consists of creating an optical illusion. The façades feature two layers of customized aluminum extrusion profiles on top of a back layer of composite aluminum cladding. The vertical profiles of the top layer are straight, but those of the back layer are angled. This results in a wave-like appearance, which changes with the viewpoint of the spectator.

In light control type of façade, automated shading and day lighting control systems are integrated and operated appropriately for all environmental conditions. A notable example is Al Bahr Towers (Case Study 2). The façade of the building showed continuous considerations for the surface that can actively respond to changes in environmental conditions. The building consists of a membrane clad dynamic façade with a similar hexagonal pattern in the constructio

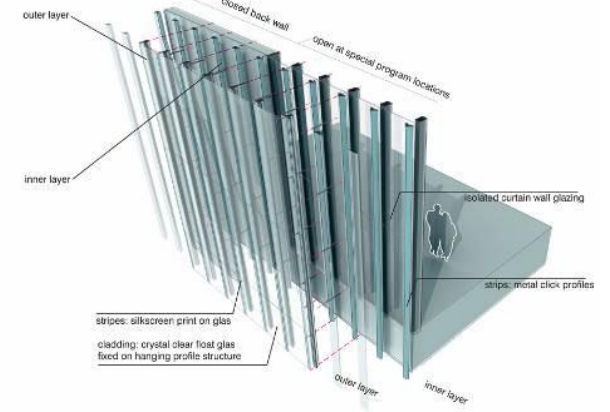

Fig (2) Galleria Centercity in Cheonan, Korea

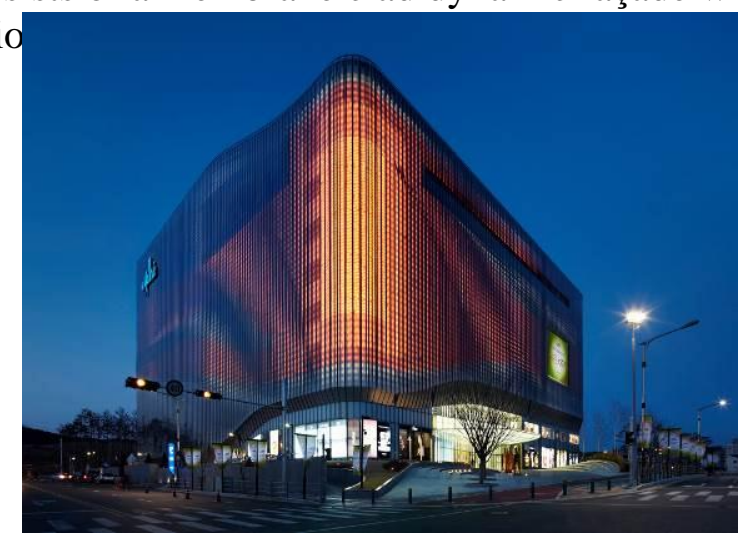

581

DOI: 10.33193/JALHSS.43.29 


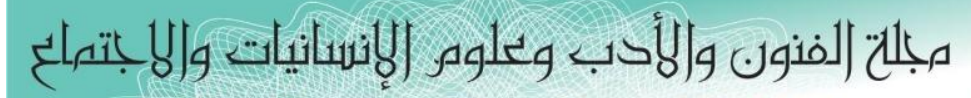

Journal of Arts, Literature, Humanities and Social Sciences

ISSN online: 2414 - 3383

ISSN print: 2616 - 3810
العدد (43) أيلول - سبتهبر 2019

C. Energy Control Kinetic Façade Another application for dynamic façades as energy conscious façades are where the envelope has construction functions such as strength and rigidity, stability and durability, control of heat, air and moisture vapor flows, control of liquid water movement cost-effectiveness, and fire resistance. The envelope is responsible for the building energy performance.

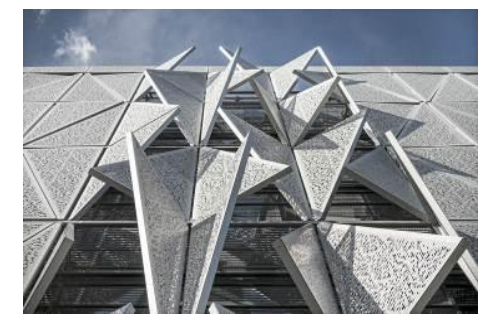

Fig (3) SDU Kolding Campus Building

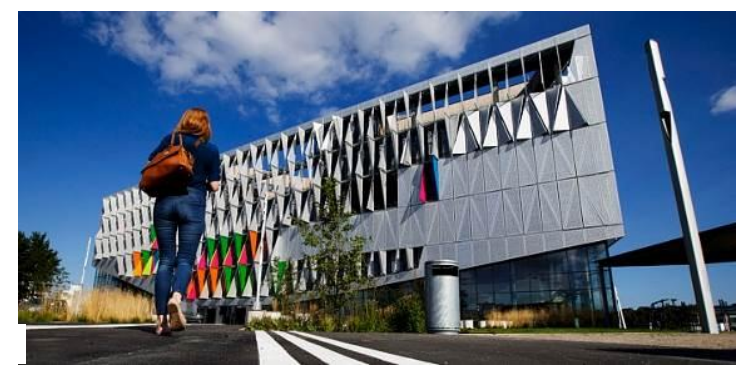

D. Wind Responsive Kinetic Façade Wind, as a natural element itself, is strong enough to provide a dynamic pattern of motion without wasting any energy. (Case Study 3) and Brisbane Domestic Terminal Carpark in Australia (2011) has installed 250,000 aluminum plates to create this wind-powered façade. The façade created a direct interface between the built and the natural environments. The façade itself constantly stays in moving motion as the wind blows. Fig (4)
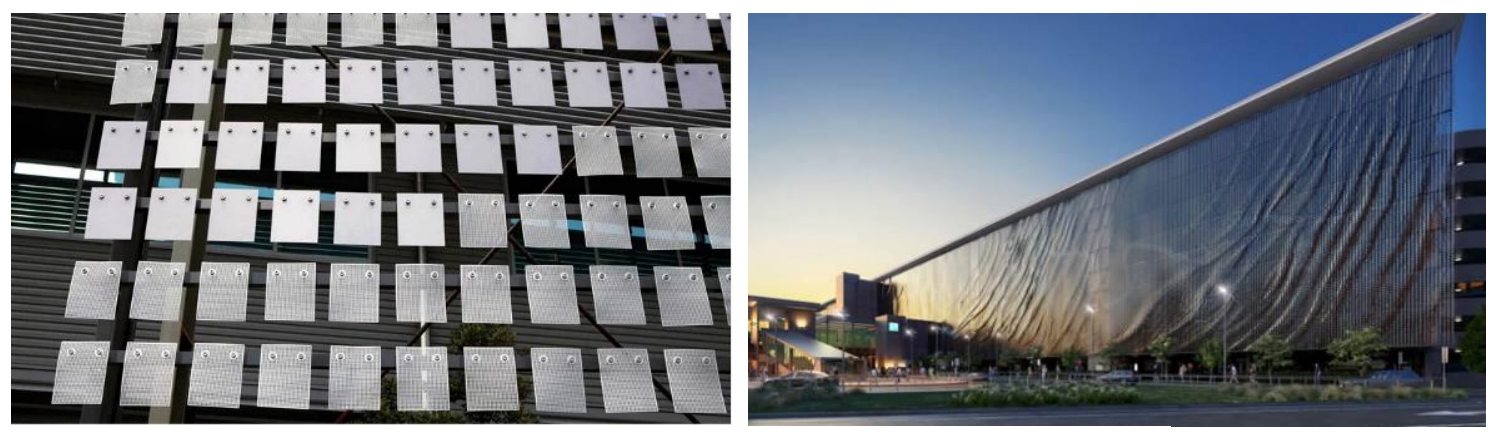

Fig (4)

Brisbane Domestic Terminal Carpark - Australia (2011)

Towards evaluating kinetic façades design that responds to environments:

There are several parameters that should be included when designing building facades. Each has the potential to define the character and affect the overall perception of a building:- 


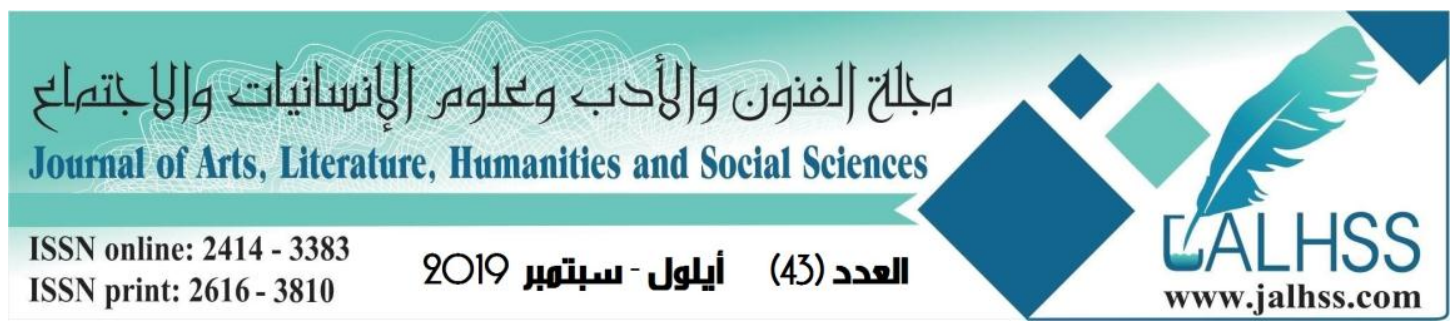

- Sun Control Thermal and visual comforts are dependent on controlling the light entering a building through its façade. The amount of light admitted to a building correlates directly with an increase in interior temperatures, affecting the comfort level of the users within. Blinds can provide a simple way to restrict sunlight subtly without affecting the overall appearance of the building. Alternatively, shading elements can be highlighted by integrating the solar strategy into the façade.

- Natural Ventilation The building skin plays an important role in terms of the natural air exchange in buildings. Ventilation strategies can also give a strong character to the elements of a façade. They can be simple, small, repetitive louvers that allow for localized air circulation, or involved mechanical systems that direct fresh air throughout the building.

- Day Lighting The use of natural daylight is important, both in terms of the comfort and in terms of contentment of the users and with regard to reducing the requirements for artificial light. Daylight systems can be achieved mainly through passive measures. A simple movable light shelf can bounce light deep into the space, illuminating the interior by taking advantage of the reflectivity of the ceiling. Daylight levels are known to affect the mental health of the users.

- Thermal Insulation Thermal insulation systems employ materials and components capable of reducing heat loss through transmittance, convection, or radiation. The invisible insulation in walls has a huge potential to affect the thermal performance of a building. A particular insulation's make up and placement within the layering of the building skin can have large consequences that are observable in the thermal performance and aesthetics of the building skin.

- Moisture Control Bitumen, a natural substance consisting mainly of hydrocarbons, is frequently used to create moisture barriers in buildings. It is often thought of the outer most skin as the water barrier, but more frequently, it is as a rainscreen. There are two kinds of moisture to contend with when trying to keep the building dry: rain and condensation. When large temperature differentials occur between the interior space and the exterior, condensation forms on the colder surface. Protection is necessary to prevent this moisture from seeping into the building. The rainscreen and moisture barrier work together to prevent the unwanted rain and condensation from entering the building.

- Possibility of Energy Generation The possibility for a building's skin to become an energy source, flexible solar thin films can be integrated into façades to simultaneously generate power and shade a building. To advance the issue of the building skin with a view to creating truly sustainable and enduring architecture, planning must be goal-oriented, responsible, and sensible. In 


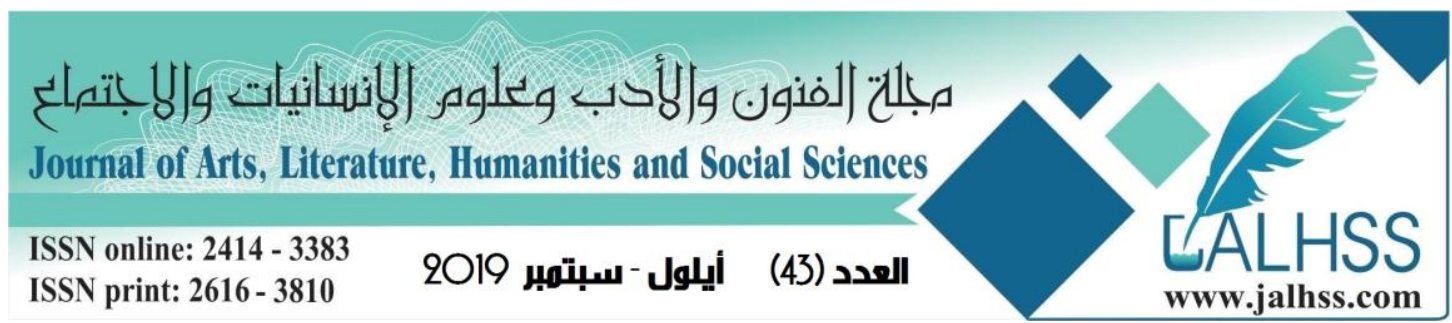

addition, a high degree of technical and creative ability is essential.

The enormous potential of the building skin must be realized from structural, functional, aesthetic and ecological perspectives to promote advances in the development of architecture that is oriented towards sustainable future.

The process of designing kinetic façades is complicated by the integration of kinetic systems and physical interactive reconfigurations for a façade's performance (i.e. responding to changes in light). Traditional development design tools center on static design, where the need to design kinetic façades is a process that involves interactive elements that are essential in order to ensure effective function. As a result, this requires an alternative approach to the process of identifying and evaluating the appropriate kinetics for a façade's system in the early design phase, in response to environmental conditions. Evaluating the interactive components of a kinetic façade involves various strategies and techniques, which inform the initial early design. This raises the question of: What are the tools that are effective in evaluating kinetic façades in response to the constant change of environmental conditions, taking into account the constraint of limited time during the early design stage?

The answer in the next case study which discuss 3 of the most important kinetic façades and how it helps improving the environment. The 3 projects listed here are exploring the potential of kinetic responses to the influence of the mechanism and design of the successive kinetic systems that are explored in Investigation One. The kinetic patterns involved in this investigation are generated during the assessment of precedent studies and literature review. The kinetic patterns are selected based on their potential for the kinetic façades to be applied for the effective control of the environmental conditions. 


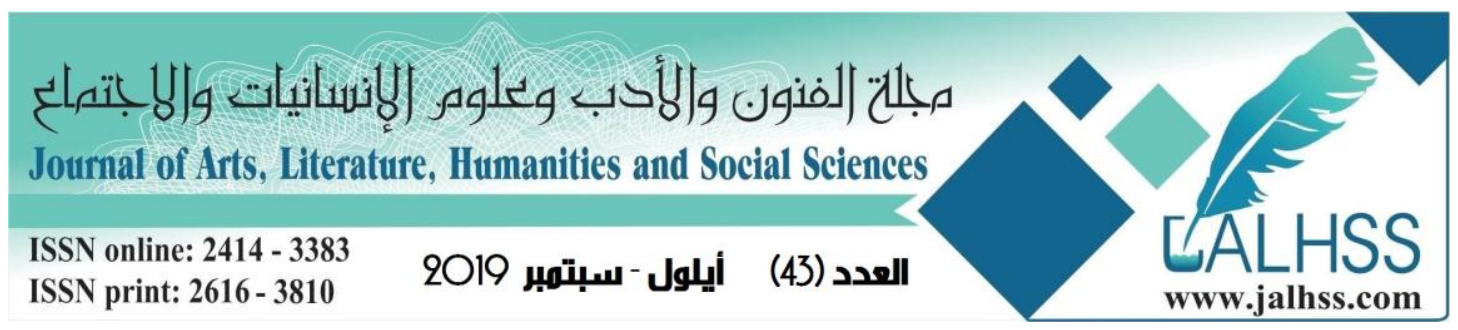

Case study (1): US Pavilion at Expo '67":

Architect: Buckminster Fuller

Location: Montreal, Canada

Project Year: 1967

Description: A giant dome roughly threequarters of a sphere, designed to look like a lacy filigree weightless against the sky. Height: 200 feet: spherical diameter; 250 feet. The volume contained within it is so spacious that it comfortably fits a sevenstory exhibition building featuring the various programmatic elements of the exhibit.

Construction: a space frame of steel pipes enclosing 1,900 molded acrylic panels.

Geometrically, the dome is an icosahedron, a 20-sided shape formed by the interspersion of pentagons into a hexagonal grid. However, the clarity of this form is obfuscated by the fragmentation of its faces, which are subdivided into a series of equilateral triangles with minor distortions that bow the individual planar sections into shells. As a result, the aggregate composition of the dome is substantially more spherical than simple icosahedra, while the smaller units create dazzling visual complexity through sheer repetitiousness. This lattice-type structure is created entirely of three-inch steel tubes, welded at the joints and thinning gently toward the top of the structure so as to optimally distribute forces throughout the system.

${ }^{*}$ By the author
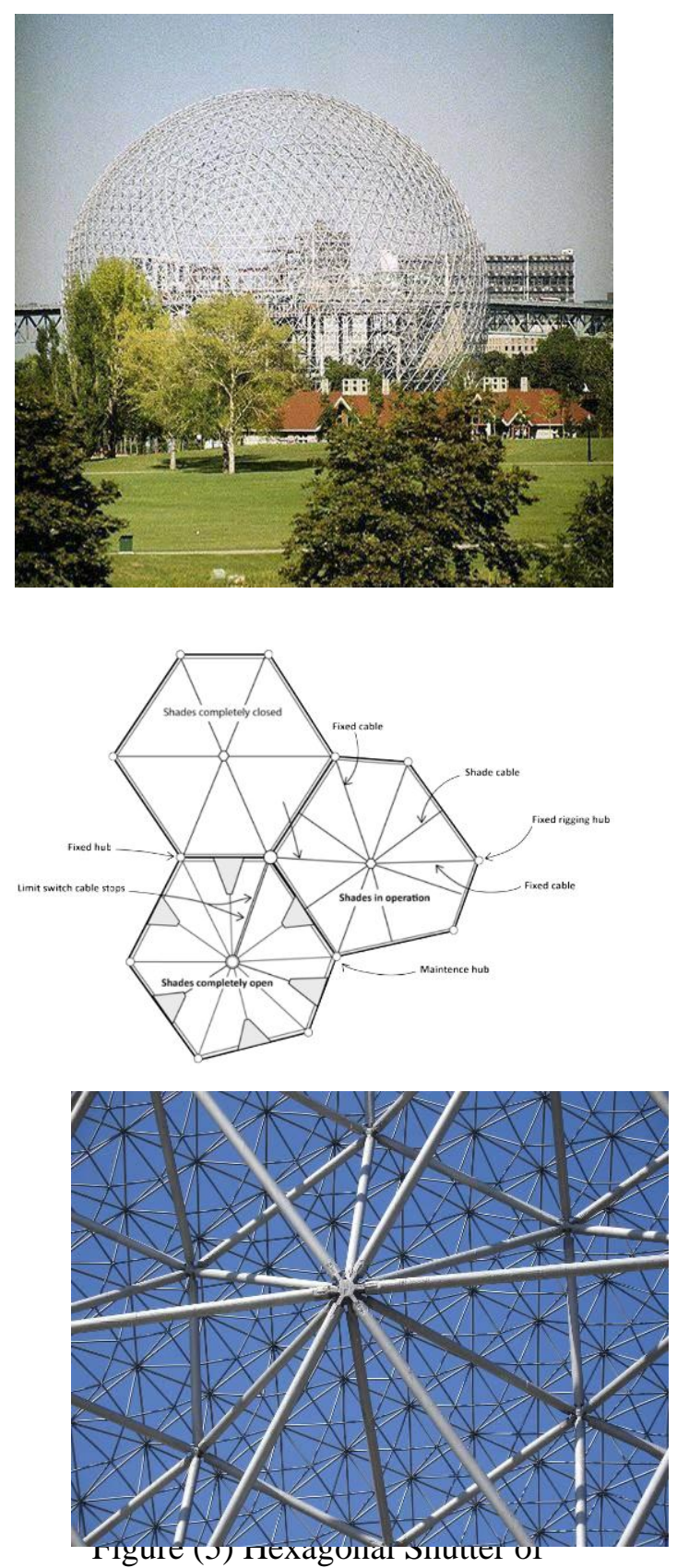

American Pavilion 1967, designed by

Buckminster Fuller (Massey, 2006) 


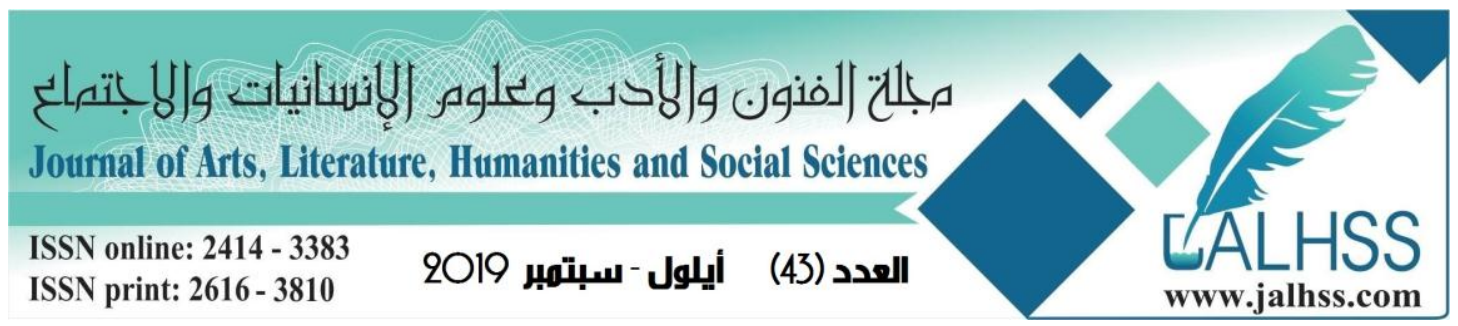

Case study (2): Al Bahr Towers*

Architect: AHR

Location: Abu Dhabi, UAE

Project Year: 2012

Description: Al Bahr Towers is the world's largest dynamic façade. The design concept is based on the fusion between bio-inspiration and performance-based technology, the design principles of $\mathrm{Al}$ Bahr Towers achieved a performance oriented, culturally relevant, technologically advanced, and aesthetically intriguing, building with a unique contextually relevant identity.

The design is based on the concept of adaptive flowers and the "Mashrabiya" - a wooden lattice shading screen, which is traditionally used to achieve privacy whilst reducing glare and solar gain. The geometry of the shading screen folds and unfolds in response to the movement of the sun, reducing solar gain by up to $50 \%$, whilst simultaneously improving admission of natural diffused light into the towers and improving visibility. The original folding concept for the dynamic Mashrabiya unit was initially explained through a simple origami model that revealed how the triangular unit would function.

Al Bahr Towers fuse the principles of bioinspiration, regional architecture, and performance oriented technology with an underlying performance criteria, grid-guide, and geometric composition that generates a highly efficient integrated system. Traditionally, circles and orbits are used to
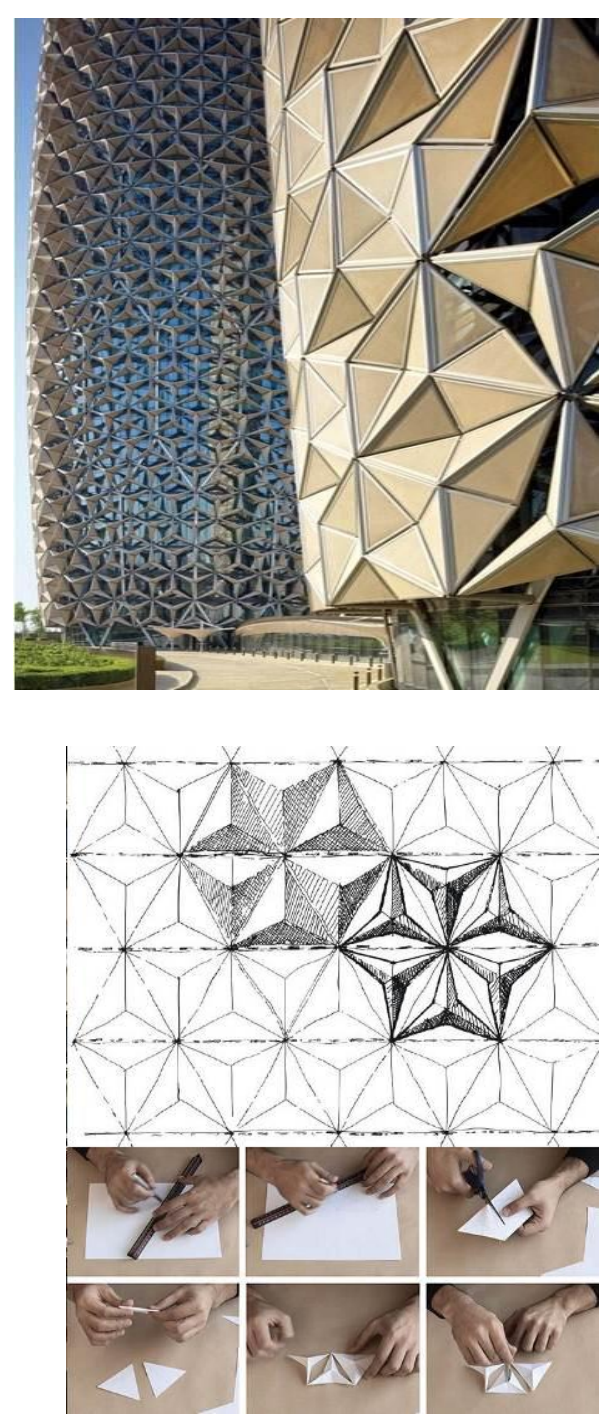

By the author 


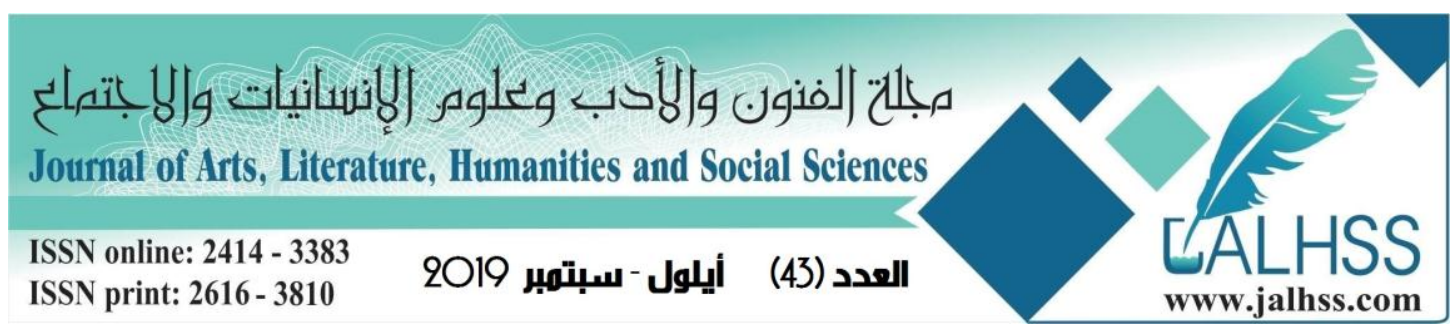

reflect the concept of unification and unity evident in nature. The plan of the towers is based on six tangential arcs, taken from three intersecting circles - a pattern which forms the basis of nearly all geometric configurations known to the region.

The 2,098 dynamic units avoid the need for heavily treated glass, thereby reducing the need for significant artificial lighting and mechanical air conditioning. Therefore, the dynamic façade improves visibility and user comfort while decreasing energy usage and plant size thus, providing an efficient system that lends itself to a more sustainable solution.

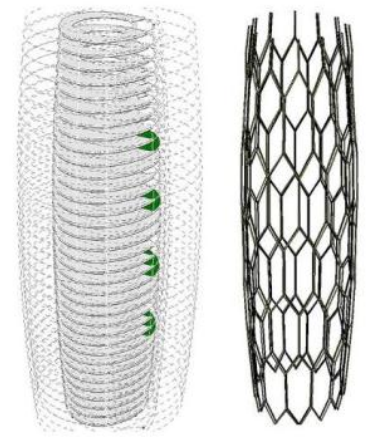

Fig (6) Al Bahr Towers, Abu Dhabi, UAE

A bespoke application was developed using Javascript and advanced parametric technologies to simulate the movement of the façade in response to the sun's path. The performance criteria and geometry build-up of the system design were conveyed using a unique project specific Geometry Construction \& Performance Manual. This freed the designto-construction process from locking it down to certain platforms and computer technologies and offered a universal data exchange language, enabling all parties to communicate more effectively. 


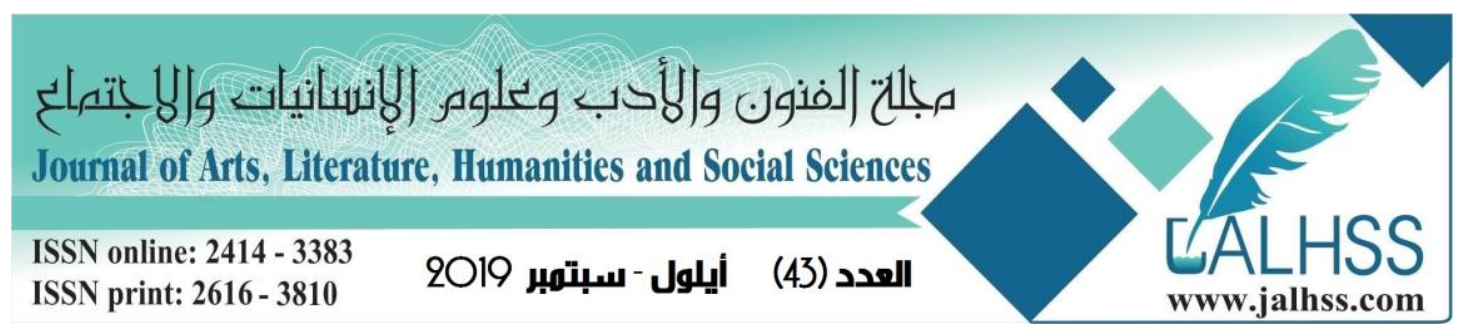

Case Study (3): Debenhams, Oxford Street 2014*:

Architect: Archial Architects

Location: UK

Project Year: 2014

Description: The first major use of a kinetic façade in the UK, thousands of aluminum tiles are hung off a framework in a way that allows them to move in the wind and create a fluid façade.

The new rainscreen was part of a $£ 40 \mathrm{~m}$ store makeover that also included an atrium, canopy, signage, extended shop windows, and a complete internal refurbishment.

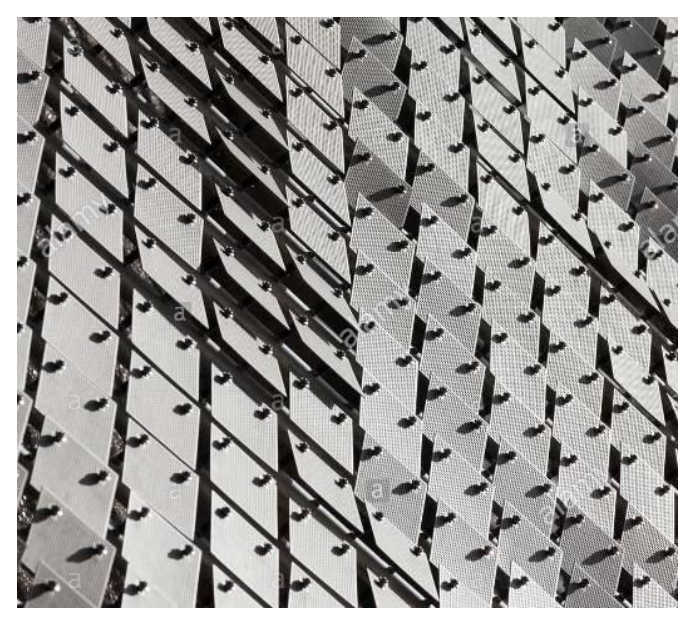

The cladding screen has been conceived as a kinetic façade comprised of 185,000 suspended aluminum shingles that will ripple gently in the wind. ${ }^{1}$

The shingles are suspended within a steel structural cladding frame, which has been projected $840 \mathrm{~mm}$ from the face of the precast reinforced concrete panels that form the building's existing façade. Although the cladding system will not require routine maintenance, the $840 \mathrm{~mm}$ gap will allow maintenance access if required.

The kinetic façade system features a series of $2 \mathrm{~mm}$-thick perforated anodized aluminum shingles measuring 127.5 by $127.5 \mathrm{~mm}$. These are loosely pinned to a rail system, 10 shingles on each rail, which in turn is fixed to a fabricated steel $\mathrm{T}$ section.

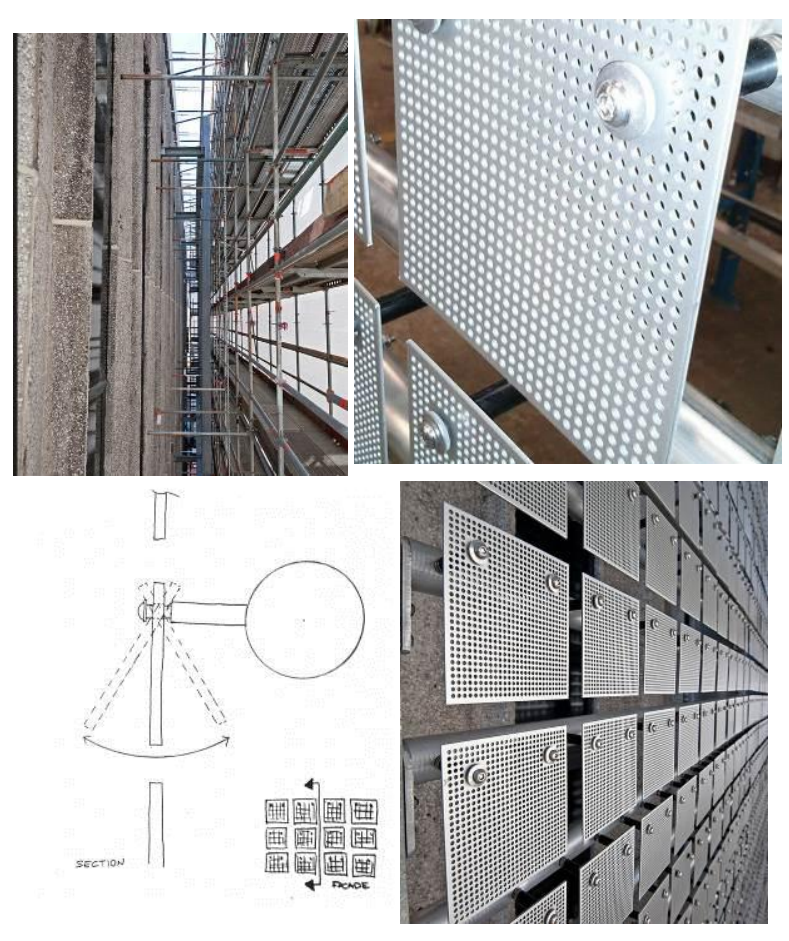

\footnotetext{
* By the author

${ }^{1}$ http://www.constructionmanagermagazine.com/onsite/five-big-tren6ds-facade-desi1gn-andconstruction6
} 


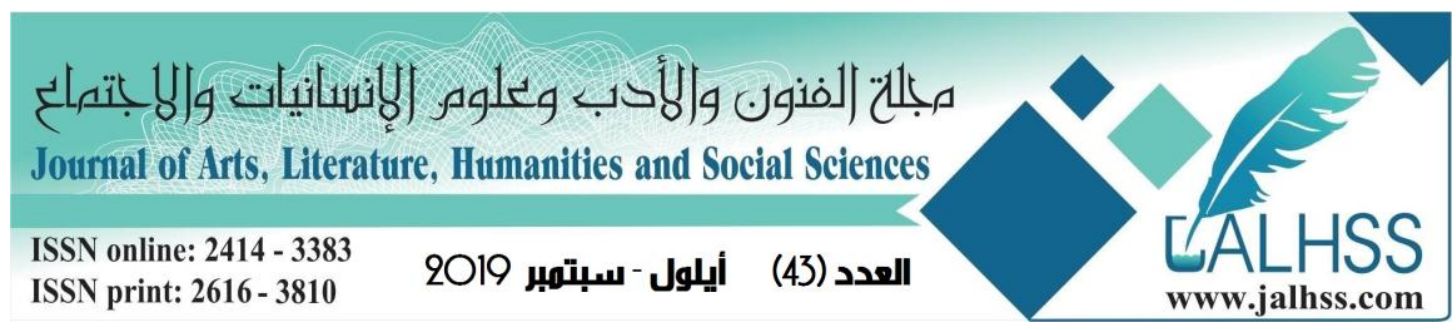

These $9.6 \mathrm{~m}$-long sections span vertically between the second and fourth floor of the building and are fixed at $1,500 \mathrm{~mm}$ centers. These are set on a series of square hollow section brackets. The shingles are light enough and have enough play in them at the fixing that they are capable of fluttering in the wind.

Fig (7) Debenhams, Oxford Street

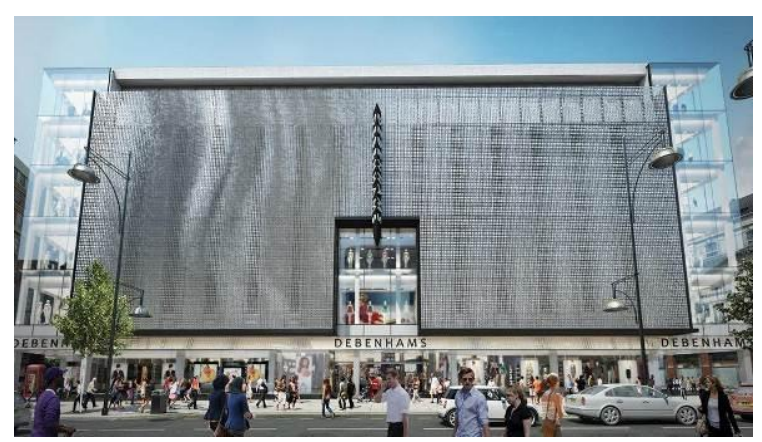

\section{Conclusion:}

As per all the applications and cases listed in this document, building façades have a great role in establishing energy effectiveness and energy execution where:

- Kinetic façades are used frequently to allow natural light. It is viewed as an effective inventive lighting and ventilation framework if appropriately structured.

- The most beneficial shading plans have demonstrated to be outside shading gadget and mobile shades introduced on structure façade, considering likewise different advantages of external shading as it could be recommended as a powerful plan arrangement against overheating.

- The best shading framework is the flexible exterior shading louvers, as it is known for being the best shading gadgets because it has an assortment of both colors and materials.

\section{Reference}

1. Alotaib, Fahad_The Role of Kinetic Envelopes to Improve Energy Performance in Buildings_Alotaibi, J Archit Eng Tech 2015.

2. Mallgrave, Harry Francis and Goodman ,David. An Introduction to Architectural Theory: 1968 to the Present. Wiley-Blackwell, United Kingdom: 2011.

3. Martin, Reinhold. Forget Fuller? Everything you always wanted to know about Fuller but were afraid to ask "Crystal Balls." ANY: Architecture New York, No. 17, pp. 35-39. 1997.

4. Massey, Jonathan Kalin- "Buckminster Fuller's Cybernetic Pastoral: The United States Pavilion at Expo67', The Journal of Architecture, 11: 4, 463 - 483 - 2006.

5. Nady, Riham , Dynamic Facades Environmental Control Systems for Sustainable Design, Renewable Energy and Sustainable Development (RESD) Volume 3 Issue 1, Special Issue, pp 118: 127- March 2017.

6. Sharaidin, Kamil _ Kinetic Facades: Towards design for Environmental 


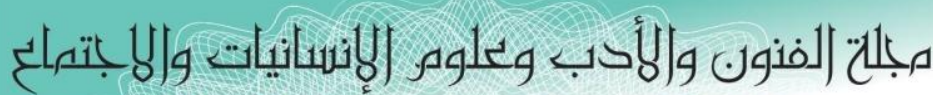

Journal of Arts, Literature, Humanities and Social Sciences

ISSN online: 2414 - 3383

ISSN print: 2616 - 3810

\section{العدد (43) أيلول - سبتمبر 2019}

Performance _ An exegesis submitted in fulfilment of the requirements for the degree of Doctor of Philosophy _ School of Architecture and Design RMIT University -2014.

\section{Websites:}

1. Buckminster, Richard- Fuller: A Visionary Architect. Environment Canada. http://www.ec.gc.ca/biosphere/default.asp?lang=En\&n=30956246-1-18November 2014.

2. Dezinti- The Climate-Responsive Kinetic Facade of SDU Kolding Campus Building- http://motioninarchitecture.com/climate-responsive-kinetic-facade-of-sdukolding-campus/ 22 May 2019.

3. Dynamic facades: The story- https://www.arch2o.com/dynamic-facades-thestory/ 22 May 2019.

4. Hamilton, Bryan - Al Bahr Towers- https://www.ahr.co.uk/Al-Bahr-Towers 22 May 2019

5. Kinetic

façadehttps://www.designingbuildings.co.uk/wiki/Kinetic_facade- 11 January 2019 6. Oxford street gets UK first moving façade https://www.constructionnews.co.uk/projects/project-reports/oxford-street-gets-uk-firstwith-wates-moving-faade/8656141.article - 20 October 2018. 